\title{
Enhanced Photocatalytic Dehalogenation of Aryl Halides by Combined Poly-p-phenylene (PPP) and $\mathrm{TiO}_{2}$ Photocatalysts.
}

John T. Petroff II, Anh H. Nguyen, Alex J. Porter, Fraisher D. Morales, Michael P. Kennedy, David Weinstein, Hossam El Nazer ${ }^{* 1}$, Ryan D. McCulla*

Photochemistry Dept., National Research Centre, 33 El Bohouth St., Dokki-Giza - Egypt P.O. 12622. Email: dr_hosamnazer@yahoo.com.

3501 Laclede Ave., Department of Chemistry, Saint Louis University, St. Louis, MO 63103, United States of America.

\section{Keywords}

Conjugated polymer photocatalyst, semiconductor photocatalyst, photoredox catalysis

\section{Abstract}

The abundant energy provided by sunlight makes visible-light driven photoredox catalysis an attractive means of performing chemical transformations. Titanium dioxide $\left(\mathrm{TiO}_{2}\right)$ and conjugated polymers are semiconducting materials that have been used as photoredox catalysts. Driving electron transfer process with photoredox catalysts and visible light has become a powerful method for achieving efficient chemical transformations. However, titanium dioxide does not readily absorb visible light, and conjugated polymers have not been extensively studied as photoredox catalysts for organic transformations. In this work, $\mathrm{TiO}_{2}$ and the conjugated polymer poly-p-phenylene (PPP) were successfully used as heterogeneous cocatalysts for the dehalogenation of some simple aryl halides using triethylamine as a sacrificial electron donor. While PPP alone exhibited some photocatalytic activity upon irradiation with visible light, the efficiency of dehalogenation was enhanced by the addition of titanium dioxide. No reaction was observed in the absence of both photocatalysts or when $\mathrm{TiO}_{2}$ was used as the sole photocatalyst. The optimum operating parameters were examined. 
Keywords: Conjugated polymer photocatalyst; semiconductor photocatalyst; photoredox catalysis

\section{Introduction}

Decreasing the environmental impact of organic reactions is a laudable objective that has been taken up by many researchers.[1] One way to achieve this aim is to use an abundant and renewable energy source, such as sunlight, to drive these reactions. Harnessing energy from the visible region of the solar spectrum is attractive because most organic compounds do not absorb visible light, which limits the occurrence of undesirable side reactions. For this reason, photocatalysts that absorb visible light have the potential for numerous applications in organic synthesis.

Visible-light driven photoredox catalysis has experienced a surge of interest since the work by MacMillan, Stephenson, and Yoon was published in 2008 and 2009.[2-4] The use of photoredox catalysts for organic transformations was made possible by the excellent stability, visible light absorption, and redox properties of $\mathrm{Ru}(\mathrm{II})$ and $\operatorname{Ir}(\mathrm{III})$ polypyridine complexes.[5] Irradiation of these organometallic complexes is typically used to induce electron transfer reactions to generate reactive ion-radicals that subsequently transform into products. For example, $\mathrm{Ru}(\mathrm{II})$ and $\operatorname{Ir}(\mathrm{III})$ complexes have been used to develop a tin-free methodology for the generation of radicals from compounds with activated carbon-halogen bonds.[6]

The replacement of toxic tin hydrides with photoredox catalysts provides more benign conditions for the generation of radicals. In 2009, the benefits of this methodology were demonstrated through the reductive dehalogenation of alkyl bromides and chlorides by the visiblelight photocatalyst $\mathrm{Ru}(\mathrm{bpy})_{3} \mathrm{Cl}_{2}$.[4] Radical generation through reduction of the organic halide by the reduced catalyst $[R u(I)]$ followed by hydrogen abstraction was suggested as the reaction mechanism. The robustness of the method was soon exploited for radical cyclizations, malonate 
addition to heterocycles, dehalogenation of vicinal halides, coupling with alkynes, coupling allylic bromides, and as part of the total synthesis of $(+)$-Gliocladin C.[7-13] The versatility of generating radicals from organohalides has prompted the investigation of organic photoredox catalysts capable of facilitating dehalogenations.[14-16]

One limiting feature of the aforementioned reactions is the substrates must be activated towards reduction. This limitation can be overcome by the use of photoredox catalysts with higher reduction potential. Recently, this was demonstrated by the use of a poly-2-phenylpyridine Ir complex used to generate radicals from unactivated alkyl, alkenyl, and aryl iodides.[17] Thus, more substrates could be accessed with photoredox catalysts with even higher reduction potentials.

Inorganic semiconductors have been used as photocatalysts for water treatment and to a lesser extent to drive organic reactions.[18] The irradiation of semiconductors excites electrons into the conduction band and concomitantly produces holes in the valence band. This allows the oxidation or reduction of adsorbed species with the proper redox potentials as shown in Scheme 1. To catalyze organic reactions, photocatalytic systems are designed to take advantage of the reactivity of the transient radical-anion $\left(A^{-*}\right)$ or radical-cation $\left(D^{-+}\right)$to generate new products $(P)$ through unimolecular rearrangements or reactions with other species at the surface or in bulk solution.

\section{Scheme 1}

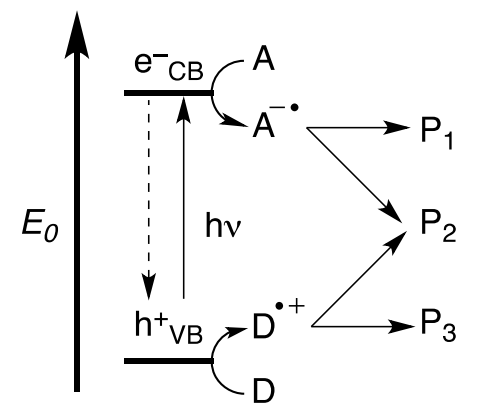

SEMICONDUCTOR PHOTOCATALYST 
Semiconductor photocatalysts have been used for various organic transformations. [18] Irradiation of the common inorganic semiconductor photocatalyst $\mathrm{TiO}_{2}$ is typically used for oxidative transformations; however, unmodified $\mathrm{TiO}_{2}$ photocatalytic systems often suffer from poor selectivity. For example, photocatalytic oxidation of benzene with commercial $\mathrm{TiO}_{2}$ leads to over-oxidation and yields only $2 \%$ phenol.[19] This poor yield was slightly improved to $34 \%$ by using mesoporous $\mathrm{TiO}_{2}$. [19] Also, the addition of $\mathrm{Pd}$ and $\mathrm{Au}$ as co-catalysts to $\mathrm{TiO}_{2}$ improved the yield of phenol to $\sim 30 \%$.[20] Improvement of the oxidation of alcohols to the corresponding aldehydes and ketones has also been improved with modified $\mathrm{TiO}_{2}$.[21] Irradiation of aerated water containing 4methoxybenzyl alcohol and nanostructured $\mathrm{TiO}_{2}$, made by boiling an aqueous solution containing $\mathrm{TiCl}_{4}$, produced the corresponding aldehyde with relatively good yields of the aldehyde (42\% after $65 \%$ substrate conversion). Commercially available $\mathrm{TiO}_{2}$ (Degussa $\left.\mathrm{P} 25\right)$ yielded poorer results (12\% in $40 \%$ substrate conversion). This same oxidation was improved to $78 \%$ yield by the use of rhodium ion-modified $\mathrm{TiO}_{2}$ as the photocatalyst.[22]

Compared to $\mathrm{TiO}_{2}$, which only has a moderate conduction band potential ( $-0.5 \mathrm{~V}$ vs. $\left.\mathrm{NHE}\right)$, the conjugated polymer poly(p-phenylene) (PPP) has a much higher conduction band potential of 2.0 vs. NHE.[23] Electron transfer to an acceptor can only occur easily if the reduction potential of the acceptor is less negative than the conduction band potential of the photocatalyst. Thus, PPP is expected to be a much stronger reductive photocatalyst than $\mathrm{TiO}_{2}$ and most other inorganic semiconductors. The potential use of conjugated polymer photocatalysts in synthetic applications was illustrated by the visible-light driven pinacol coupling of benzaldehyde by using PPP as the photoredox catalyst.[23-25] The reaction required the use of a sacrificial electron donor triethylamine $\left(\mathrm{Et}_{3} \mathrm{~N}\right)$ and was accelerated by the addition of Lewis and Brønsted acids.

One drawback of PPP system was the need for several days of irradiation for the reaction to complete. While not used for organic transformation, improvement in the degradation of organics by conjugated polymer and $\mathrm{TiO}_{2}$ nanocomposites has been observed. For example, polyaniline/TiO and poly(3-hexythiophene) $/ \mathrm{TiO}_{2}$ nanocomposites were shown to improve the photocatalytic degradation of phenol and methyl orange, respectively.[26,27] As detailed above, co-catalysts and 
the formation of composites has been shown improve the photocatalytic performance of $\mathrm{TiO}_{2}$ and PPP. These observation suggested use of PPP and $\mathrm{TiO}_{2}$ as co-catalysts or as part of a composite could lead to an improvement in photocatalysis. In the present work, the photocatalytic dehalogenation of some simple aryl halides was performed to test the hypothesis that an increase in photocatalytic activity would be observed when PPP and $\mathrm{TiO}_{2}$ were used as cocatalysts.

\section{Methods and Materials}

2.1 Materials: All aryl halides and solvents were obtained from Sigma-Aldrich Chemical Company or Fisher Scientific and were used as received without further purification. The solvents used were HPLC grade (99.9+\%). Titanium (IV) oxide, anatase (98\%) was purchase from Acros chemical and was used as received.

2.2 Poly-(p-phenylene) preparation: Poly-(p-phenylene) was prepared using a procedure similar to Yamamoto's method.[28] Briefly, 1,4-dibromobenzene (11.8 g) and magnesium turnings (1.22 g) were combined in dry THF $(40 \mathrm{~mL})$ under a dry argon atmosphere and stirred at room temperature for 1 hour. Next, $50 \mathrm{mg}$ of $\mathrm{Ni}(\mathrm{bpy}) \mathrm{Cl}_{2}$ was added at room temperature. The reaction was allowed to proceed at reflux for another 16-30 hours before being cooled to room temperature. The reaction was quenched by adding the reaction mixture to ethanol $(600 \mathrm{~mL})$. The resulting polymer solid was collected by filtration, and then washed sequentially with $0.1 \mathrm{M}$ $\mathrm{HCl}_{(\mathrm{aq})}$, water, and ethanol prior to being dried under reduced pressure. The solids were purified by Soxhlet extraction with toluene for 30 hours.

2.3 General photocatalytic reaction procedures: Photocatalytic reduction reactions were carried out using a LZ4-X Luzchem Photoreactor with eight fluorescent bulbs generating approximately 
$70 \mathrm{~W} / \mathrm{m}^{-2}$ from $400-440 \mathrm{~nm}$. Reaction solutions were added to disposable borasillicate test tubes and sealed with rubber septa. Prior to photolysis, all of the samples were sparged with argon for at least 30 minutes and sonicated to break up the heterogeneous photocatalyst powder. During the photoreaction, the samples were stirred and the temperature held constant at $25-30{ }^{\circ} \mathrm{C}$. The product analysis was performed using an Agilent 1200 Series HPLC fitted with a UV-Vis diode array detector.

\section{Results and Discussion}

The addition of Brønstead acids had been shown to quicken the pinacol coupling of simple aryl aldehydes using PPP. However, even with the addition of acid, the photoreaction of benzaldehyde $(107 \mathrm{mg})$ to hydrobenzoin still required 36 hours to reach an $81 \%$ isolated yield of benzyl alcohol.[24,25] The long irradiation times were hypothesized to result from poor adsorption of the substrates to the PPP surface.[24,25] Titanium dioxide has many photocatalyst applications and often has good adsorption properties, and thus, it was posited that using $\mathrm{TiO}_{2}$ as a co-catalyst would improve the performance of the PPP photocatalytic system.

3.1 Optimization of catalyst loading. The dehalogenation of methyl 4-chlorobenozate (1) to methyl benzoate (2) by PPP acting as the photoredox catalyst was chosen to test if the addition of $\mathrm{TiO}_{2}$ as a co-catalyst would accelerate the reaction. In the typical photoreaction, a $5 \mathrm{~mL}$ solution of acetonitrile containing $1(9 \mathrm{mM})$, and triethylamine $(1 \mathrm{M})$, was prepared in a glass test-tube. The PPP and $\mathrm{TiO}_{2}$ were then added as insoluble powders. The effect of formic acid (200 $\mathrm{mM})$ on the reaction was also examined. 


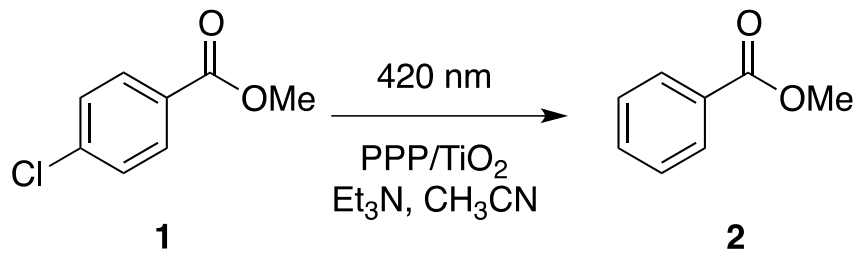

To examine the effect of $\mathrm{TiO}_{2}$, the initial rate of the reaction was estimated by determining the concentration of 2 by HPLC after four hours of irradiation with different catalyst loadings. A representative HPLC trace is shown in Figure 1. Each reaction was performed at least three times, and the total amount of photocatalyst used was always equal to $6 \mathrm{mg}$. The average concentration of 2 after four hours of irradiation is given in Table 1 . In the absence of PPP (Table 1, entries 9-12), 2 was not detected by HPLC. However, the formation of 2 was detected after 4 hours of irradiation when only PPP was used as a photocatalyst (Table 1, entries 1 \& 2). This indicated that PPP itself was capable of acting as a photocatalyst for this reaction. Compared to PPP alone, a mixture of PPP and $\mathrm{TiO}_{2}$ consistently yielded higher concentrations of 2 .

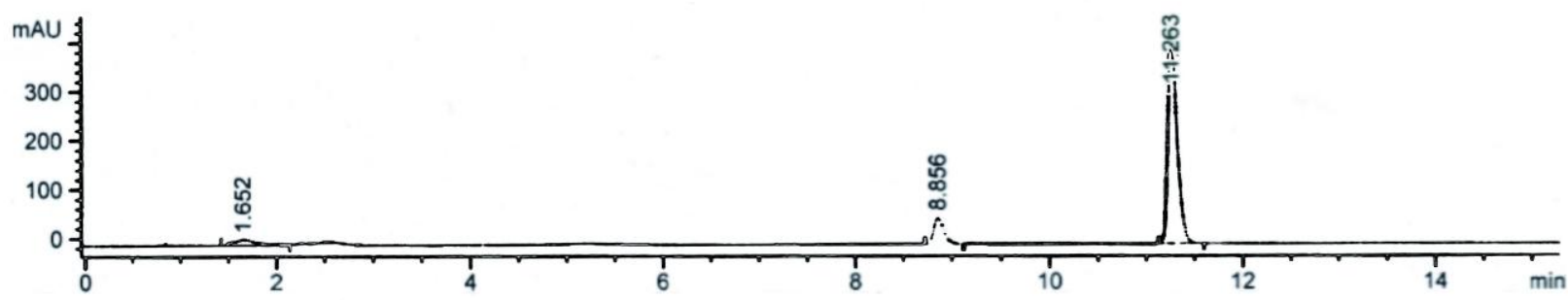

Figure 1. Representative HPLC trace of sample analyzed after 4 hours of irradiation carried out at $420 \mathrm{~nm}$ on a $5 \mathrm{~mL}$ acetonitrile solution containing $9 \mathrm{mM} \mathrm{1,1.5} \mathrm{mg}$ of $\mathrm{TiO}_{2}, 4.5 \mathrm{mg} \mathrm{PPP}$, and $1 \mathrm{M} \mathrm{Et}_{3} \mathrm{~N}$. Peaks at 1.652, 8.856, and 11.263 minutes are $\mathrm{Et}_{3} \mathrm{~N}, \mathbf{2}$, and 1, respectively. 
Table 1. Optimization of catalyst loading for the dehalogenation of $1 .^{\text {a }}$

\begin{tabular}{cccc}
\hline Entry & Catalyst(s) & Formic acid $(\mathrm{mM})$ & {$[\mathbf{2}]^{\mathrm{b}}$} \\
\hline 1 & $6.0 \mathrm{mg}$ PPP & 0 & $0.29 \pm 0.15^{\mathrm{c}}$ \\
2 & $6.0 \mathrm{mg}$ PPP & 200 & $0.4 \pm 0.3^{\mathrm{c}}$ \\
3 & $4.5 \mathrm{mg} \mathrm{PPP}+1.5 \mathrm{mg} \mathrm{TiO} 2$ & 0 & $0.5 \pm 0.2^{\mathrm{c}}$ \\
4 & $4.5 \mathrm{mg} \mathrm{PPP}+1.5 \mathrm{mg} \mathrm{TiO} 2$ & 200 & $0.9 \pm 0.3^{\mathrm{c}}$ \\
5 & $3 \mathrm{mg} \mathrm{PPP}+3 \mathrm{mg} \mathrm{TiO} 2$ & 0 & $1.0 \pm 0.3^{\mathrm{c}}$ \\
6 & $3 \mathrm{mg} \mathrm{PPP}+3 \mathrm{mg} \mathrm{TiO} 2$ & 200 & $1.4 \pm 0.6^{\mathrm{c}}$ \\
7 & $1.5 \mathrm{mg} \mathrm{PPP}+4.5 \mathrm{mg} \mathrm{TiO} 2$ & 0 & $0.34 \pm 0.17^{\mathrm{c}}$ \\
8 & $1.5 \mathrm{mg} \mathrm{PPP}+4.5 \mathrm{mg} \mathrm{TiO} 2$ & 200 & $0.8 \pm 0.3^{\mathrm{c}}$ \\
9 & $6.0 \mathrm{mg} \mathrm{TiO} 2$ & 0 & n.d. ${ }^{\mathrm{d}}$ \\
10 & $6.0 \mathrm{mg} \mathrm{TiO2}$ & 200 & n.d. \\
11 & None & 0 & n.d. \\
12 & None & 200 & n.d. \\
\hline
\end{tabular}

a. Solutions containing formic acid, $1 \mathrm{M}$ triethylamine, and $9 \mathrm{mM}$ of $\mathrm{MCB}$, and the photocatalysts were sonicated and sparged with argon for 30 minutes prior to irradiation with eight $420 \mathrm{~nm}$ bulbs. ${ }^{\text {b. }}$ Concentration of methyl benzoate (2) after 4 hours of irradiation as determined by HPLC analysis. ${ }^{\text {c. }} 95 \%$ confidence intervals. ${ }^{\text {d. }}$ not detected.

The optimal ratio of PPP to $\mathrm{TiO}_{2}$ for the production 2 was $1: 1$. When $3 \mathrm{mg}$ of both PPP and $\mathrm{TiO}_{2}$ was used, the measured concentrations of 2 after fours hours of irradiation were 1.0 and $1.4 \mathrm{mM}$ in the absence and presence of formic acid, respectively. This was over three times larger than for PPP alone, which yielded 0.29 and $0.4 \mathrm{mM}$ of 2 in the absence and presence of formic acid, respectively. Adjusting the ratio to favor PPP or $\mathrm{TiO}_{2}$ while keeping the total amount of photocatalyst constant yielded less 2 (Table 1, entries 3,4,7, and 8). However, in both cases, about double the amount of $\mathbf{2}$ was observed compared to PPP alone. As reflected in confidence intervals, the variation of the measured concentrations of 2 from reaction to reaction was relatively large for all of the different catalyst loadings.

The addition of formic acid resulted in the production of more 2 on average for a given photocatalyst loading ratio. For example, at the optimal ratio of $\mathrm{PPP}$ to $\mathrm{TiO}_{2}(3 \mathrm{mg}: 3 \mathrm{mg}), 1.4$ 
$\mathrm{mM}$ of 2 was generated when $200 \mathrm{mM}$ of formic acid was added to the solution compared to only $1.0 \mathrm{mM}$ when formic acid was absent. These results were consistent with those observed in the pinacol coupling of benzaldehyde; except in the present work, formic acid had a lesser effect.[24] In fact, the 95\% confidence intervals in some cases (Table 1, entries 5 \& 6) indicated that there was no significant difference with and without formic acid.

3.2 Effect of varied electron donor concentration. For semiconductor photoredox catalysts, charge recombination of the electron promoted to the conduction band $\left(\mathrm{e}_{\mathrm{cb}}^{-}\right)$and the valence band hole $\left(\mathrm{h}^{+}{ }_{\mathrm{vb}}\right)$ decreases the efficiency of photoredox catalysis. Therefore, increasing the concentration of the sacrificial electron donor $\left(\mathrm{Et}_{3} \mathrm{~N}\right)$ was expected to accelerate the reaction. After four hours of irradiation, the concentration of 2 increased linearly with increasing concentration of $\mathrm{Et}_{3} \mathrm{~N}$ as shown in Figure 2. This result was consistent with the role of the triethylamine acting as the primary electron donor in the photocatalyzed dehalogenation reaction.

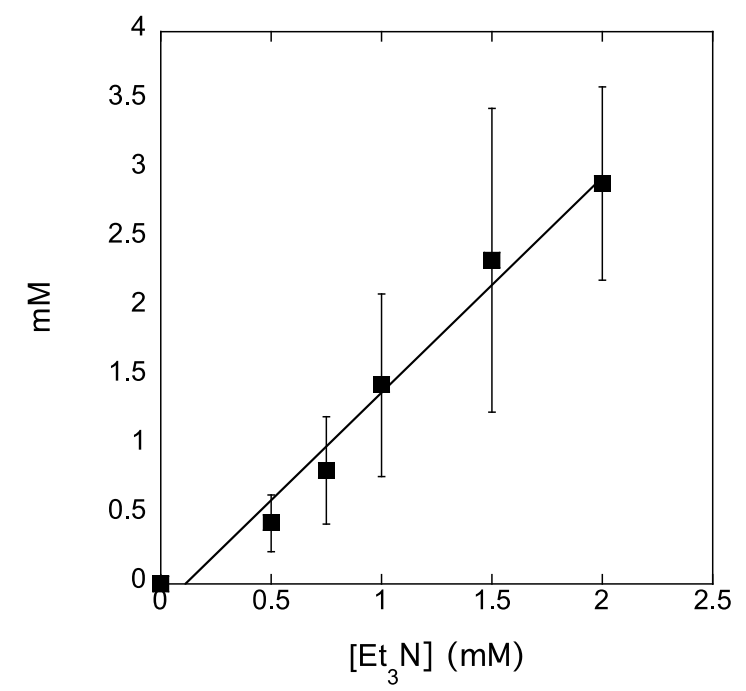

Figure 2. Affect of $\mathrm{Et}_{3} \mathrm{~N}$ concentration on the $\mathrm{PPP} / \mathrm{TiO}_{2}$ photocatalyzed dehalogenation of methyl 4-chlorobenozoate (1). Irradiations were carried out at $420 \mathrm{~nm}$ on $5 \mathrm{~mL}$ acetonitrile solutions containing $9 \mathrm{mM} \mathrm{1}, 200 \mathrm{mM}$ formic acid, and $3 \mathrm{mg}$ of $\mathrm{TiO}_{2}$ and $\mathrm{PPP}$, and a variable amount of $\mathrm{Et}_{3} \mathrm{~N}$. The concentration of 2 was after 4 hours of irradiation determined by HPLC analysis. 
3.3 Dehalogenation of aryl chlorides and bromides with varied redox potentials. The initial reaction optimization studies indicated that PPP catalyzed the dehalogenation of $\mathbf{1}$ by facilitating electron transfer from the triethylamine to 1 . Therefore, it was hypothesized that any aryl halide with a reduction potential more positive than the conduction band potential of PPP (-2.0 vs. $\mathrm{NHE}$ )[23] would undergo dehalogenation under these conditions. To test this hypothesis, aryl halides with reported reduction potential values, which ranged from -2.16 to $-1.15 \mathrm{~V}$ vs. $\mathrm{Ag} / \mathrm{AgBr}\left(\mathrm{Et}_{4} \mathrm{NBr}\right.$ supporting electrolyte),[29,30] were chosen to examine the effect of aryl halide reduction potential on the photocatalytic dehalogenation reaction using $\mathrm{PPP} / \mathrm{TiO}_{2}$ co-catalysts. For the chosen aryl halides, all reported reduction potential values were determined using the same $\mathrm{Ag} / \mathrm{AgBr}$ system, in which the potential of the $\mathrm{Ag} / \mathrm{AgBr}$ system was estimated at $-520 \mathrm{mV}$ vs. SCE or $-276 \mathrm{mV}$ vs. NHE.[31,32] In addition to $\mathbf{1}$, the aryl halides (3-10) used in this study are shown in Scheme 2. 


\section{Scheme 2}<smiles>Cc1ccc(Cl)cc1</smiles>

3<smiles>Brc1ccccc1</smiles>

5<smiles>Brc1cccc(Br)c1</smiles>

7<smiles>N#Cc1ccc(Br)cc1</smiles>

9<smiles>Cc1ccc(Br)cc1</smiles>

4<smiles>Brc1ccc(Br)cc1</smiles>

6<smiles>N#Cc1ccc(Cl)cc1</smiles>

8<smiles>COC(=O)c1ccc(Br)cc1</smiles>

10

The effect of aryl halide reduction potential was investigated using the general photocatalytic reaction procedure described in the section 2.3. Experimental solutions were composed of $1 \mathrm{M}$ triethylamine, $200 \mathrm{mM}$ formic acid, $3 \mathrm{mg}$ of $\mathrm{TiO}_{2}, 3 \mathrm{mg}$ of PPP, and $10 \mathrm{mM}$ aryl halide in $5 \mathrm{~mL}$ of acetonitrile. Photolysis of each experimental solution was repeated a minimum of three times. After irradiation, the concentration of the dehalogenated products was determined. The results of these experiments are given in Table 2.

The salient result of these experiments was that aryl halides with a reduction potential more negative than $-1.5 \mathrm{~V}$ vs. $\mathrm{Ag} / \mathrm{AgBr}$ did not undergo dehalogenation under these conditions (Table 2, entries 1-4). Conversely, if the reduction potential of the aryl halide was more positive 
than $-1.5 \mathrm{~V}$ vs. $\mathrm{Ag} / \mathrm{AgBr}$, then the aryl halide underwent dehalogenation. As a point of reference, the potential of PPP can be approximated as $-1.7 \mathrm{~V}$ vs. $\mathrm{Ag} / \mathrm{AgBr}$.

Table 2. Dehalogenation of aryl halides. ${ }^{a}$

\begin{tabular}{ccccc}
\hline Entry & Aryl halide & $\begin{array}{c}\text { Reduction } \\
\text { potential }\end{array}$ & [product] $^{\mathrm{b}}$ & Yield $^{\mathrm{c}}$ \\
\hline 1 & 4-chlorotoluene (3) & $-2.16^{\mathrm{d}}$ & n.d. & -- \\
2 & 4-bromotoulene (4) & $-1.84^{\mathrm{d}}$ & n.d. & -- \\
3 & 4-bromobenzene (5) & $-1.81^{\mathrm{d}}$ & n.d. & -- \\
4 & 1,4-dibromobenzene (6) & $-1.54^{\mathrm{d}}$ & $\mathrm{n} . \mathrm{d}$. & -- \\
5 & 1,3-dibromobenzene (7) & $-1.45^{\mathrm{d}}$ & $1.4 \pm 0.4$ & 56 \\
6 & 4-chlorobenzonitrile (8) & $-1.36^{\mathrm{d}}$ & $1.4 \pm 0.5$ & 31 \\
7 & Methyl 4-chlorobenzoate (1) & $-1.32^{\mathrm{e}}$ & $1.4 \pm 0.6$ & 39 \\
8 & 4-bromobenzonitrile (9) & $-1.26^{\mathrm{d}}$ & $1.8 \pm 0.9$ & 79 \\
9 & Methyl 4-bromobenzoate (10) & $-1.15^{\mathrm{d}}$ & $0.92 \pm 0.05$ & 68 \\
\hline
\end{tabular}

a. Irradiation of solutions containing $200 \mathrm{mM}$ formic acid, $1 \mathrm{M}$ triethylamine, and $9 \mathrm{mM}$ of aryl halide for four hours at $420 \mathrm{~nm}$. Solutions were sonicated and sparged with argon for 30 minutes prior to irradiation. ${ }^{\text {b. }}$ Concentration of dehalogenated product after 4 hours of irradiation as determined by HPLC analysis. c. Yield of dehalogenated product on large-scale reactions $(150 \mathrm{mg})$ in $13 \mathrm{~mL}$ of $\mathrm{CH}_{3} \mathrm{CN}$. ${ }^{\mathrm{d}}$. Reduction potential values from reference $25 \mathrm{vs}$. $\mathrm{Ag} / \mathrm{AgBr}$. ${ }^{\text {e. }}$ Reference 26. ${ }^{\text {f. }}$ not detected.

The resulting dehalogenated products of 1,3-dibromobenzene (7), 4-chlorobenzonitrile (8), methyl 4-chlorobenzoate (1), 4-bromobenzonitrile (9), and methyl 4-bromobenzoate (10) are shown in Figure 3. All of these have a literature reported reduction potential at least $0.2 \mathrm{~V}$ more positive than the conduction band potential of PPP. The inability of $\mathrm{PPP} / \mathrm{TiO}_{2}$ to dehalogenate aryl halides with reduction potentials more negative than $-1.5 \mathrm{~V}$ vs $\mathrm{Ag} / \mathrm{AgBr}$ indicates that PPP initiates the dehalogenation by a single electron transfer to the aryl halide in the reactions containing aryl halides $\mathbf{7 - 1 0}$ and $\mathbf{1}$. Single electron transfer to the aryl halides 3-5 from the conduction band of PPP (-1.7 vs. $\mathrm{Ag} / \mathrm{AgBr})$ would be thermodynamically unfavorable, and thus, the failure of 3-5 to dehalogenate was expected. Electron transfer to $6(-1.54 \mathrm{~V} \mathrm{vs}$. $\mathrm{Ag} / \mathrm{AgBr})$ from the 
conduction band of PPP should be thermodynamically favorable; however, the kinetics of this reduction may not be slow when the potential difference between PPP and the aryl halide is smaller than $0.2 \mathrm{~V}$.

After 4 hours of irradiation, the average concentration of the resulting dehalogenated product ranged from 0.92 to $1.8 \mathrm{mM}$ for the aryl halides with reduction potentials more positive than $-1.5 \mathrm{~V}$ vs. $\mathrm{Ag} / \mathrm{AgBr}$ (Table 2, entries 5-9). However, the significance of these differences could not be established due to the large 95\% confidence intervals relative to the determined concentrations. The average concentrations and corresponding confidence intervals in Table 2 were calculated using data from three to five experiments. The relatively large errors associated with the measured concentrations likely arise from the heterogeneous nature of the reaction conditions. 
<smiles>CCN(C)P(=O)(O[Na])O[Na]</smiles><smiles>CCN(C)P(C)(=O)OCc1ccccc1</smiles><smiles>CCN(CC)P(=O)(O)OC(=O)c1ccccc1C(=O)OC</smiles><smiles>CCN(C)P(C)(=O)c1ccccc1</smiles>

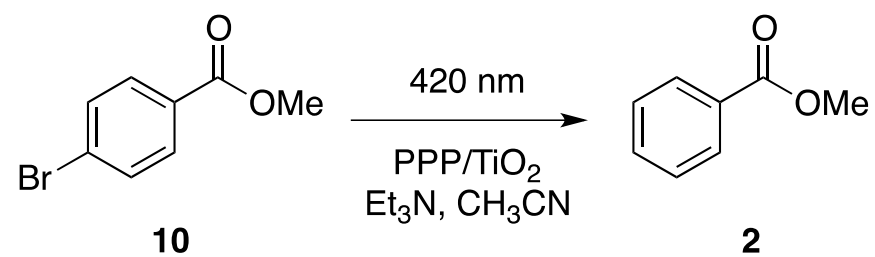

Figure 3. Dehalogenation of aryl halides by $\mathrm{TiO}_{2} / \mathrm{PPP}$ photocatalysis

Given the heterogeneous nature of the reaction solution, a scale up of the reaction to give similar yields could not be assumed. Therefore, in order to test the scale-up potential, 150 $\mathrm{mg}$ of each respective reactant were irradiated with $420 \mathrm{~nm}$ light in a sonicated, rapidly stirring mixture containing $6 \mathrm{mg} \mathrm{PPP,} 6 \mathrm{mg} \mathrm{TiO}$, and the appropriate concentrations of formic acid (200 $\mathrm{mM})$ and $\mathrm{Et}_{3} \mathrm{~N}(1 \mathrm{M})$ in acetonitrile totaling $5 \mathrm{~mL}$. All samples were sparged with argon prior to irradiation. This photoreaction took place in a $13 \mathrm{~mm}$ borosilicate test tube and lasted for one month with each reaction giving a product with a yield between $31 \%$ and $79 \%$. These yields 
were only loosely correlated to the reduction potential of the reactants, likely because as the magnitude of the reduction potential increases the yield decreases.

3.4 Mechanistic Implications. The increasing rate with additional sacrificial electron donor and the dependence on the reduction of the aryl halides to undergo dehalogenation allow for the inference that PPP acted as a photoredox catalyst in these reactions. This indicates the reaction proceeds first by excitation of PPP, followed by electron transfer from $\mathrm{Et}_{3} \mathrm{~N}$ to PPP, and then from the PPP to the aryl halide, forming a radical-anion. The aryl halide radical-anion dehalogenates by releasing a halide anion, resulting in the putative aryl radical. In a final step, the aryl radical abstracts a hydrogen atom from the solvent or triethylamine. This proposed process is depicted in Scheme 3. Although the presence of $\mathrm{TiO}_{2}$ does increase the rate of the reaction, its exact role is unknown.

\section{Scheme 3}

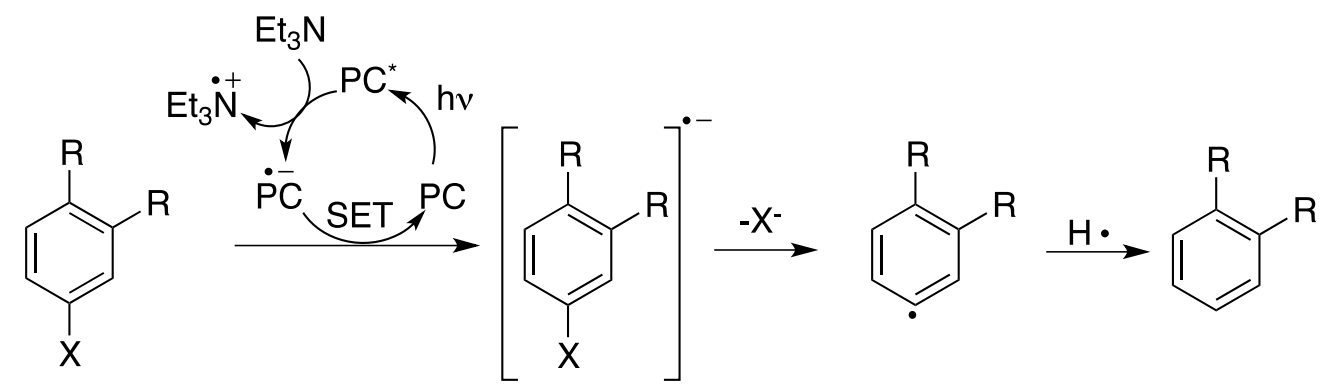

4. Conclusions: The conjugated polymer PPP and $\mathrm{TiO}_{2}$ were successfully used as heterogeneous co-catalysts for the dehalogenation of aryl halides. Only aryl halides with reduction potential values $0.2 \mathrm{~V}$ more positive than the conduction band potential of PPP underwent dehalogenation. The rate of reaction increased with an increasing concentration of the sacrificial electron donor triethylamine. The effect of $200 \mathrm{mM}$ formic acid on the reaction was unclear. Results were consistent with a mechanism involving a single electron transfer (SET) from the PPP to the aryl halide, leading to the loss of a halide ion and the formation of the 
corresponding radical, which subsequently yields the dehalogenation product via abstraction of a hydrogen atom. While PPP exhibits some photocatalytic activity upon irradiation with visible light, the rate of dehalogenation was enhanced by the addition of $\mathrm{TiO}_{2}$, though the exact role of $\mathrm{TiO}_{2}$ is unclear at this time. No reaction was observed in absence of both photocatalysts or when $\mathrm{TiO}_{2}$ was used as the sole photocatalyst, and the optimal ratio of PPP to $\mathrm{TiO}_{2}$ was $1: 1$.

\section{Acknowledgements}

This work is based upon work supported by the National Science Foundation under grant no. (CHE-1255270). The authors thank the National Science Foundation for support under grant CHE-0963363 for renovations to the research laboratories in Monsanto Hall. H.E.N. was supported by the U.S. - Egypt Science and Technology Junior Scientist Visits Program.

\section{References}

[1] P. Anastas, N. Eghbali, Green Chemistry: Principles and Practice, Chem. Soc. Rev. 39 (2010) 301-312. doi:10.1039/B918763B.

[2] D.A. Nicewicz, D.W.C. Macmillan, Merging photoredox catalysis with organocatalysis: the direct asymmetric alkylation of aldehydes, Science. 322 (2008) 77-80. doi:10.1126/science.1161976.

[3] M.A. Ischay, M.E. Anzovino, J. Du, T.P. Yoon, Efficient visible light photocatalysis of [2+2] enone cycloadditions, J. Am. Chem. Soc. 130 (2008) 12886-12887. doi:10.1021/ja805387f.

[4] J.M.R. Narayanam, J.W. Tucker, C.R.J. Stephenson, Electron-transfer photoredox catalysis: development of a tin-free reductive dehalogenation reaction, J. Am. Chem. Soc. 131 (2009) 8756-8757. doi:10.1021/ja9033582. 
[5] J.M.R. Narayanam, C.R.J. Stephenson, Visible light photoredox catalysis: applications in organic synthesis, Chem. Soc. Rev. 40 (2011) 102-113. doi:10.1039/b913880n.

[6] C. Dai, J.M.R. Narayanam, C.R.J. Stephenson, Visible-light-mediated conversion of alcohols to halides, Nature Chem. 3 (2011) 140-145. doi:10.1038/nchem.949.

[7] J.W. Tucker, J.M.R. Narayanam, S.W. Krabbe, C.R.J. Stephenson, Electron Transfer Photoredox Catalysis: Intramolecular Radical Addition to Indoles and Pyrroles, Org. Lett. 12 (2010) 368-371. doi:10.1021/ol902703k.

[8] J.W. Tucker, C.R.J. Stephenson, Tandem visible light-mediated radical cyclizationdivinylcyclopropane rearrangement to tricyclic pyrrolidinones, Org. Lett. 13 (2011) 5468-5471. doi:10.1021/ol202178t.

[9] L. Furst, B.S. Matsuura, J.M.R. Narayanam, J.W. Tucker, C.R.J. Stephenson, Visible light-mediated intermolecular $\mathrm{C}-\mathrm{H}$ functionalization of electron-rich heterocycles with malonates, Org. Lett. 12 (2010) 3104-3107. doi:10.1021/ol101146f.

[10] L. Furst, J.M.R. Narayanam, C.R.J. Stephenson, Total Synthesis of (+)-Gliocladin C Enabled by Visible-Light Photoredox Catalysis, Angew. Chem. Int. Edit. 50 (2011) 9655-9659. doi:10.1002/anie.201103145.

[11] H. Jiang, Y. Cheng, Y. Zhang, S. Yu, De NovoSynthesis of Polysubstituted Naphthols and Furans Using Photoredox Neutral Coupling of Alkynes with 2-Bromo-1,3-dicarbonyl Compounds, Org. Lett. 15 (2013) 4884-4887. doi:10.1021/ol402325z.

[12] G. Pratsch, L.E. Overman, Synthesis of 2,5-Diaryl-1,5-dienes from Allylic Bromides Using Visible-Light Photoredox Catalysis, J. Org. Chem. 80 (2015) 11388-11397. doi:10.1021/acs.joc.5b01962.

[13] T. Maji, A. Karmakar, O. Reiser, Visible-Light Photoredox Catalysis: Dehalogenation of Vicinal Dibromo-, $\alpha$-Halo-, and a, $\alpha$-Dibromocarbonyl Compounds, J. Org. Chem. 76 (2011) 736-739. doi:10.1021/jo102239x.

[14] M. Neumann, S. Füldner, B. König, K. Zeitler, Metal-Free, Cooperative Asymmetric 
Organophotoredox Catalysis with Visible Light, Angew. Chem. Int. Edit. 50 (2010) 951954. doi:10.1002/anie.201002992.

[15] Z.J. Wang, S. Ghasimi, K. Landfester, K.A.I. Zhang, A conjugated porous polybenzobisthiadiazole network for a visible light-driven photoredox reaction, J. Mater. Chem. A 2 (2014) 18720-18724. doi:10.1039/C4TA03887H.

[16] E.H. Discekici, N.J. Treat, S.O. Poelma, K.M. Mattson, Z.M. Hudson, Y. Luo, et al., A highly reducing metal-free photoredox catalyst: design and application in radical dehalogenations, Chem. Commun. 51 (2015) 11705-11708. doi:10.1039/C5CC04677G.

[17] J.D. Nguyen, E.M. D'Amato, J.M.R. Narayanam, C.R.J. Stephenson, Engaging unactivated alkyl, alkenyl and aryl iodides in visible-light-mediated free radical reactions, Nature Chem. 4 (2012) 854-859. doi:10.1038/nchem.1452.

[18] M.A. Fox, M.T. Dulay, Heterogeneous photocatalysis, Chem. Rev. 93 (1993) 341-357. doi:10.1021/cr00017a016.

[19] Y. Shiraishi, N. Saito, T. Hirai, Adsorption-driven photocatalytic activity of mesoporous titanium dioxide, J. Am. Chem. Soc. 127 (2005) 12820-12822. doi:10.1021/ja053265s.

[20] R. Su, L. Kesavan, M.M. Jensen, R. Tiruvalam, Q. He, N. Dimitratos, S, Wendt, M. Glasius, C.J. Kiely, G.J. Hutchings, F. Besenbacher, Selective photocatalytic oxidation of benzene for the synthesis of phenol using engineered Au-Pd alloy nanoparticles supported on titanium dioxide, Chem. Commun. 50 (2014) 12612-12614. doi:10.1039/C4CC04024D.

[21] G. Palmisano, S. Yurdakal, V. Augugliaro, V. Loddo, L. Palmisano, Photocatalytic Selective Oxidation of 4-Methoxybenzyl Alcohol to Aldehyde in Aqueous Suspension of Home-Prepared Titanium Dioxide Catalyst, Adv. Synth. Catal. 349 (2007) 964-970. doi:10.1002/adsc.200600435. 
[22] H. Al-Ekabi, N. Serpone, E. Pelizzetti, C. Minero, M.A. Fox, R.B. Draper, Kinetic studies in heterogeneous photocatalysis. 2. Titania-mediated degradation of 4-chlorophenol alone and in a three-component mixture of 4-chlorophenol, 2,4-dichlorophenol, and 2,4,5-trichlorophenol in air-equilibrated aqueous media, Langmuir. 5 (1989) 250-255. doi:10.1021/la00085a048.

[23] T. Shiragami, A. Kabumoto, O. Ishitani, C. Pac, S. Yanagida, Novel visible-light-driven photocatalyst. Poly (p-phenylene)-catalyzed photoreductions of water, carbonyl compounds, and olefins, J. Phys. Chem. 94 (1990) 2068-2076.

[24] W.D. Rouch, M. Zhang, R.D. McCulla, Conjugated polymers as photoredox catalysts: a new catalytic system using visible light to promote aryl aldehyde pinacol couplings, Tet. Lett. 53 (2012) 4942-4945. doi:10.1016/j.tetlet.2012.06.144.

[25] M. Zhang, W.D. Rouch, R.D. McCulla, Conjugated Polymers as Photoredox Catalysts: Visible- Light- Driven Reduction of Aryl Aldehydes by Poly ( $p$ - phenylene), Eur. J. Org. Chem. (2012) 6187-6196. doi:10.1002/ejoc.201200437.

[26] X. Li, D. Wang, G. Cheng, Q. Luo, J. An, Y. Wang, Preparation of polyaniline-modified TiO2 nanoparticles and their photocatalytic activity under visible light illumination, Appl. Catal. B-Environ. 81 (2008) 267-273. doi:10.1016/j.apcatb.2007.12.022.

[27] J. Zhang, S. Cao, S. Xu, H. Yang, L. Yang, Y. Song, L. Jiang, Y. Dan, Study on stability of poly(3-hexylthiophene)/titanium dioxide composites as a visible light photocatalyst, Appl. Surf. Sci. 349 (2015) 650-656. doi:10.1016/j.apsusc.2015.04.192.

[28] T. Yamamoto, Y. Hayashi, A. Yamamoto, A Novel Type of Polycondensation Utilizing Transition Metal-Catalyzed C-C Coupling. I. Preparation of Thermostable Polyphenylene Type Polymers, Bull. Chem. Soc. Jpn. 51 (1978) 2091-2097.

[29] J.W. Sease, F.G. Burton, S.L. Nickol, Mechanism of electrolytic reduction of carbonhalogen bond. II. A rho sigma study, J. Am. Chem. Soc. 90 (1968) 2595-2598. 
[30] J. Gassmann, J. Voss, Electroreduction of Organic Compounds, 36. Electroreduction of Chlorinated Methyl Benzoates, Z. Naturforsch. B 63 (2008) 1291-1299.

[31] H. Günther, J. Voss, Esr studies on carboxylic esters. VIII: Esr studies on thioamides. VII: Radical anions of 1, 1-dithio-and 1, 1, 2-trithio-oxalic esters and amides, J. Chem. Res, Synop. 68-69 (1987) 775-789.

[32] J. Voss, R. Edler, EPR studies on carboxylic esters. Part 17. EPR spectra and spin densities in the radical anions of thio and dithiocoumarins, J. Chem. Res. (2007) 226228. doi:10.3184/030823407X209660. 


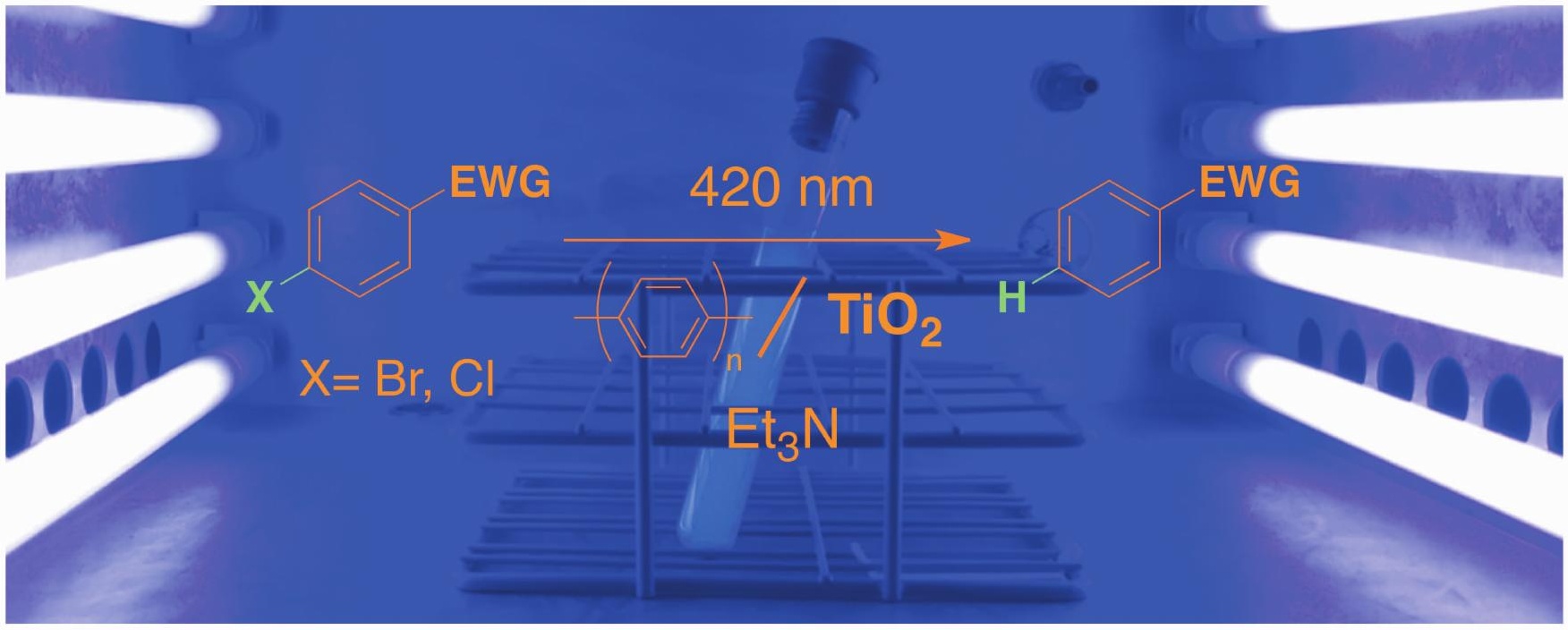

